\title{
A case study on water use efficiency in extreme water-saving cultivation of tomato plants
}

\author{
Qichen $\mathrm{Li}^{1}$, T. Sugihara ${ }^{2}$, S. Shibusawa ${ }^{2}$ and Minzan $\mathrm{Li}^{1}$ \\ ${ }^{1}$ Key Laboratory of Modern Precision Agriculture System Integration Research of Ministry of Education, China Agricultural \\ University, Beijing, P.R. China \\ ${ }^{2}$ Institute of Agriculture, Tokyo University of Agriculture and Technology, Fuchu, Tokyo, Japan
}

\section{Summary}

In horticulture, the definition of water use efficiency (WUE) is context-dependent, which causes confusions in the studies of deficit irrigation. This paper focuses on the precise relationship between individual crop growth and water absorption, aiming to experimentally verify WUE analysis based on actual crop water absorption from micro soil water dynamics in the crop rooting zone and to provide a case study of WUE assessment when crop water absorption was extremely low. In this paper, water consumption of tomato plants was observed and analyzed using a high-resolution soil moisture sensor matrix method. The experiment system was placed in an enclosed, climate-controlled environment. The system created an extreme water-saving condition by controlling moisture in the crop rooting zone to ensure a small level of crop growth. Irrigation water volume in the rooting zone was manually determined by measuring soil moisture dynamics. Relationship between WUE and root water uptake was analyzed based on the rooting zone moisture dynamics. WUE was finally determined as the ratio of crop yield to total water absorption. Comparisons were made to previous, highefficiency crop production under different irrigation conditions. In this study, the crops showed extremely low WUE under the extreme water-saving condition. The experiment verified the feasibility of using micro soil water dynamics to analyze crop WUE and using WUE as an index of crop physiological characteristics under severe survival conditions. We propose using WUE as an index throughout the cultivation process to assess the effectiveness of irrigation management in response to crop water absorption.

\section{Keywords}

water use efficiency, crop water absorption, sensor measurement, quantitative assessment, assessment index, precision irrigation

\section{Introduction}

Agriculture represents a major consumer of the freshwater resources, accounting for about $70 \%$ of the total water withdrawal (AQUASTAT, 2016). With increasing water demand from other sectors, agriculture must meet the growing demand for food using less water allocation (Frenken and Gillet, 2012). Given these factors, precision agriculture must improve crop production with limited water resource.

\section{Significance of this study}

What is already known on this subject?

- Water use efficiency (WUE) is commonly defined as the ratio of $\mathrm{CO}_{2}$ absorption to transpiration at the leaf scale, or the ratio of biomass to evapotranspiration at the plant or field scale. However, the interactions between roots and soil water and the distribution mechanism of photosynthesis products vary with growth stages and cultivation conditions, creating dynamic crop physiological characteristics and growth statuses. Traditional definitions of WUE do not capture these characteristics and statuses.

\section{What are the new findings?}

- Based on the dynamics of soil water in the small area around crop roots, a WUE assessment method examining actual crop water absorption and crop growth was developed and experimentally verified. Crops showed extremely low WUE when water absorption was close to the critical level of crop survival. WUE can be used as an index to reflect crop physiological characteristics and statuses under water-saving conditions.

What is the expected impact on horticulture?

- We focused on both the technical and economic aspect of WUE. The proposed WUE index can be used as control information and/or a parameter in irrigation systems, especially in dry land cultivation where water application is highly restricted. Precise WUE can more accurately evaluate cultivation performance. By charting crop's physiological characteristics, the index can be used to evaluate the effectiveness of water management in relation to crop water needs in deficit irrigation. The index can also contribute to crop growth control at drought-tolerant stages to postpone harvest according to shipment schedules. Detailed crop water consumption also contributes to quantitative evaluations of cost and benefit in resource management.

Precision irrigation technologies have been developed for this purpose (Raine et al., 2007; O’Shaughnessy et al., 2015), but few of them have considered the outflow of irrigation water and crop response during the cultivation process. Hence, improving water use efficiency (WUE) in agricultural production by managing irrigation according to detailed crop water requirement is a major research interest (Shukri et al., 2013, 2014). 
WUE does not have a single definition. Its definition depends on the context in which it is discussed (Bacon, 2004), which creates confusions when researchers try to study or apply the concept in their own research programs. In plant physiology, WUE has been defined as the ratio of biomass to water loss through transpiration (Stanhill, 1986; Morison et al., 2007; Sinclair, 2018). It was also used to describe the exchange rate of $\mathrm{CO}_{2}$ and water under stomata regulation on a leaf scale (Bacon, 2004; Morison et al., 2007). In practical application, it has been defined as the amount of yield produced per unit of water lost through estimated evapotranspiration based on water balance or energy balance (Howell, 2001; Geerts and Raes, 2009; Lenka et al., 2020; Kukal and Irmak, 2020). However, water from evapotranspiration is not actually used by plants, which defeats the terminology "water use" (Stanhill, 1986; Bacon, 2004; Morison et al., 2007). In irrigation, WUE or water productivity is defined as crop yield per unit of irrigation water (Morison et al., 2007; Howell, 2011). But crop yield also depends on available water in soil, and irrigation water is not necessarily all used for productive transpiration of the crop, but also lost through soil evaporation, deep percolation from the rooting zone, and run-off (Burke et al., 1999; Morison et al., 2007).

Crops have different growth stages. As growth stages change, the interaction between root and soil moisture and the distribution of photosynthesis products change, and water management should be changed accordingly. For example, at the seedling stage, water management aims at reproductive growth and should fully support the growth of roots, leaves, stems, flower buds, and other important organs. During flowering, fruiting, and fruit enlargement, along with flower bud splitting, emergence of new leaves, and elongation of the stem, water management should meet the needs of vegetative and reproductive growth of the crop (Jensen et al., 2010; Coyago-Cruz et al., 2019).

When crops are not under water stress, its water absorption depends mainly on environmental factors. However, under water stress, especially extreme water stress, crops reduce their growth rate to maintain survival due to homeostasis (Maggio et al., 2018). The deficit irrigation method is based on such principles and, by managing water stress, attempts to stabilize the balance between crop vegetative growth and reproductive growth (Geerts and Raes, 2009; Jensen et al., 2010). This approach aims to maximize net profit by optimizing water application when water is a limiting resource such as in arid land. Theoretically, the optimal water application occurs at the point of optimum WUE of the cultivated crop. However, what is the amount of water that can maximize WUE in deficit irrigation is not clear because few studies have been conducted under extreme watersaving conditions (Geerts and Raes, 2009). In addition, the uncertainties from water loss during irrigation hinders the precise analysis of WUE. It has been reported that crops may develop a protection mechanism in stressful environments (Elsheery and Cao, 2008; Omar et al., 2011, 2013; Elsheery et al., 2020a, b; Naser et al., 2016; Helaly et al., 2017), which may over-reduce crop growth to ensure survival from the stress (Maggio et al., 2018). Therefore, understanding crops' growth characteristics under restricted water usage conditions is needed in order to contribute to precise assessment of crop-water relations.

Soil water dynamics in the crop rooting zone directly affect crop growth (Jensen et al., 2010; Liu et al., 2018). Crop absorbs water from the roots and distributes it to various organs to maintain the physiological activities necessary for its growth. The study of the physiological characteristics of the root system can be dated back to $19^{\text {th }}$ century Darwin's study "The power of movements in plants", which stated that the root tips of plants can sense the surrounding soil moisture and modify the direction of root elongation (Baluška et al., 2009). Moreover, crop roots can adjust water absorption according to changes in soil moisture and maintain crop water homeostasis (Singh et al., 2020). Research has confirmed the molecular mechanism of root systems in controlling leaf stomatal apertures (Jensen et al., 2010; Takahashi et al., 2018), while the stomata oscillation phenomenon is closely related to the water absorption capacity of the root system (Hirose et al., 1991). The soil water dynamics in the small area around the roots directly affect the physiological activities of the crop, which are in turn closely related to WUE. Therefore, understanding the micro soil water dynamics in the crop rooting zone and seeking corresponding water management methods to efficiently meet crops' different water needs during the growth cycle can help improve crop yield and quality and reduce water consumption (Coyago-Cruz et al., 2019).

Given these factors, in this study, WUE is defined as the ratio of crop growth or yield to root water absorption, which is the available water in the rooting zone that can be used by crops for growth and yield. We assumed that WUE obtained this way can more effectively reflect crops' physiological characteristics and function as an index to assess crop growth status and evaluate the effectiveness of water management in response to crop water absorption requirements.

In order to test our assumption, we must first measure crops' water usage during the crop growth cycle. Leaf temperature and sap flow measurement were often used in the evaluation of crop water status (Jones, 2004). However, these methods involve complex detection systems, and the physical values obtained by these methods do not reflect rooting zone water uptake and outflow behavior, so they do not provide information about irrigation volume and timing (Jones, 2004). To evaluate root water uptake and irrigation water redistribution, methods such as water tracers (Brunel et al., 1995; Rothfuss and Javaux, 2016), electrical resistance imaging (Werban et al., 2008; Greve et al., 2011; Cassiani et al., 2016; Consoli et al., 2017), and root water uptake modeling (Vrugt et al., 2001; Albasha et al., 2015; Cai et al., 2018; Sonkar et al., 2019) have been used. However, water tracers require field sampling of soil and plants, which is labor and time intensive. The electrical resistance method requires calibration of soil parameters to obtain spatial soil moisture distribution (Zhao et al., 2019). Moreover, most root water uptake modeling approaches use single-point soil moisture measurement for parameter identification, which is insufficient especially in heterogeneous soil. As a result, real time measurement of the spatial distribution of soil water in the crop rooting zone has not been achieved.

Because the water loss from rooting zone is difficult to assess in conventional irrigation, that hinders the precise assessment of crop-water relation, this study suggests using a high-resolution measurement system to measure the micro soil water dynamics in the crop rooting zone and assess crops' detailed water consumption. The system uses minimally sized soil moisture sensors placed in a matrix inside and outside the rooting zone to obtain precise, real-time signals of the temporal and spatial moisture dynamics around the crop roots. Prior to this study, the authors have used this method to detect oscillations of soil moisture caused by the cyclic water absorption activities of blueberry crop in heterogeneous soil (Usui et al., 2017), to detect the movement of 
the wetting front in homogeneous dried soil with restricted irrigation (Li et al., 2018a), and to analyze root hydrotropism in high soil water potential gradient near the wetting front of irrigation water (Li et al., 2018b). This water-saving

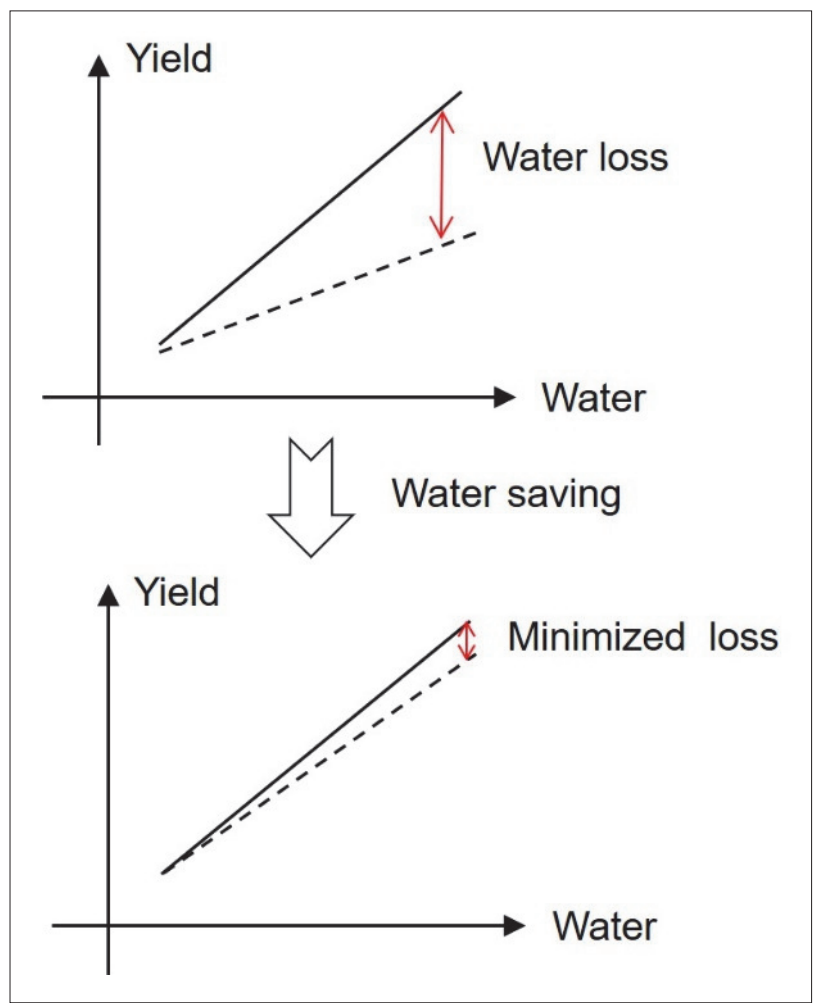

FIGURE 1. Major point of our aim: minimized resource loss in both technical and economic aspect. approach minimized the water loss, and the water applied was only used for crop transpiration and growth. In other words, since water loss is minimized in this case, the precise analysis of crop response to water becomes possible (Figure 1). On the other hand, crop growth and yield are two types of product that obtained from photosynthesis. It is difficult to separate them in the evaluation. In this study, we define WUE using only yield as a performance index because the growth is an uncertain factor which is difficult to determine. Therefore, the uncertainties from water loss and growth measurement can be minimized to develop a precise model of WUE.

Focusing on both technical and economic aspects of WUE, the objectives of this paper are: (1) to experimentally verify the previously developed high-resolution soil moisture sensor matrix method in the analysis of WUE, defined as the ratio of crop growth to root water absorption; (2) to provide, based on the results obtained from the first objective, a case study of WUE assessment when crop water absorption was extremely low. Our experiment verified the feasibility of using micro soil water dynamics to analyze crop WUE and using WUE as an index of crop physiological characteristics under severe survival conditions. The WUE obtained using our method can be used as a physiological index to evaluate the effectiveness of irrigation management in response to water absorption when water resource is limited.

\section{Materials and methods}

\section{Experimental system}

The experimental system consisted of cultivars (two tomato samples, 'Anemo', Japanese variety), environmental control components (Figure 2, parts 5-8, and rooting zone

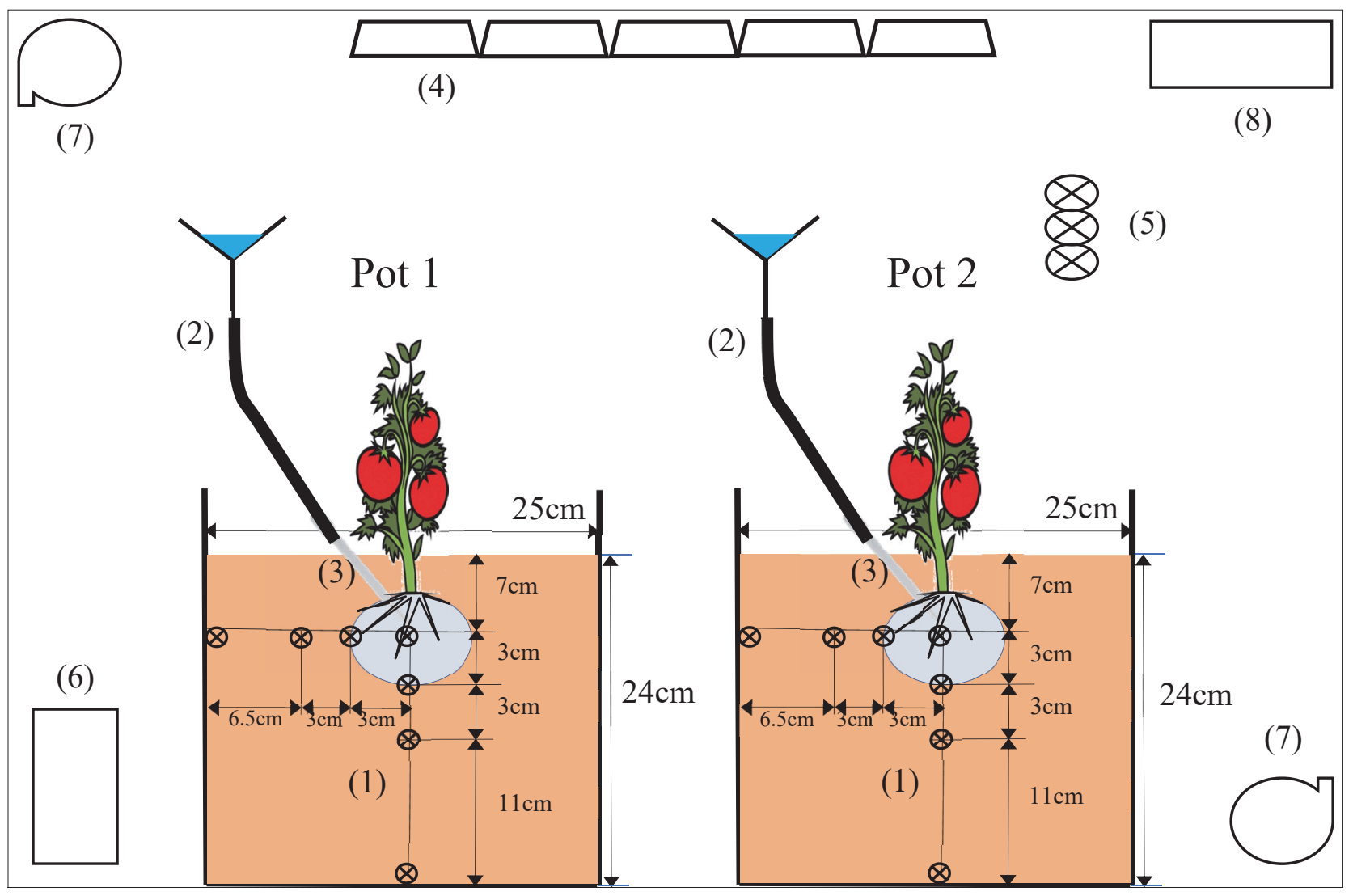

FiguRE 2. Experimental system. (1) Soil moisture sensors; (2) Water supply tube; (3) Pipette; (4) Fluorescent lamp; (5) Environmental sensors; (6) (7) (8) Temperature/Humidity conditioning equipment. 
TABLE 1. Mean value of the environmental parameters inside the growth chamber.

\begin{tabular}{lccccc}
\hline & Time & $\begin{array}{c}\text { Temperature } \\
\left({ }^{\circ} \mathrm{C}\right)\end{array}$ & $\begin{array}{c}\text { Humidity } \\
(\%)\end{array}$ & $\begin{array}{c}\text { Quantum } \\
\left(\text { umol m}^{-2} \mathrm{~s}^{-1}\right)\end{array}$ & $\begin{array}{c}\mathrm{CO}_{2} \\
(\mathrm{ppm})\end{array}$ \\
\hline Control condition 1 (Light on) & $8: 00 \mathrm{am}-10: 00 \mathrm{pm}$ & 30 & 36 & 191 & 412 \\
Control condition 2 (Light off) & $10: 00 \mathrm{pm}-8: 00 \mathrm{am}$ & 22 & 60 & 0.5 & 416 \\
\hline
\end{tabular}

moisture measurement sensors (Figure 2, part 1). The tomatoes were grown in cylindrical pots that are $25 \mathrm{~cm}$ in diameter and height (pot 1 and pot 2 in Figure 2). An industrially regulated soil, burnt red clay was used, which had a homogeneous composition and granularity with no organic fiber elements. The soil was dried in oven at $110^{\circ} \mathrm{C}$ for $24 \mathrm{~h}$ and then passed through a 1-mm sieve. Soil was placed into pots with a slight compaction. The packed dry bulk density was $0.75 \mathrm{~g} \mathrm{~cm}^{-3}$. Sample tomatoes were transplanted into the pots at 30 days after sowing. Prior to transplantation, roots were carefully cleaned of the original sowing soil.

Water source was made by a round formed fibrous cloth (A-1, Toyobo, Tokyo, Japan), which was equipped at the tip of a plastic pipette to supply water into the rooting zone directly (Figure 2, part 3). Infiltration of water through the fibrous cloth can produce uniform water globes by capillary water flow (Li et al., 2018a). The size of the water globes depends on the amount of water supply and crop water absorption. The water supply was set at $10 \mathrm{~mL}$ per event, 4-7 events a day. It has been already confirmed that the rooting zone mostly distributed inside the water globe (Li et al., 2018b). We supposed this phenomenon was caused by the water globe which influenced the root distribution. A capacitancetype soil moisture sensor matrix (EC-5, Decagon) was placed at the water source, $3 \mathrm{~cm}, 6 \mathrm{~cm}, 12.5 \mathrm{~cm}$ horizontally, and $3 \mathrm{~cm}, 6 \mathrm{~cm}, 17 \mathrm{~cm}$ vertically from the water source (Figure 2 , part 1). The sampling time of the soil moisture sensors was 5 min. Irrigation timing was manually determined, by observing the crop growth and soil moisture condition. Nutrients were supplied by adding liquid fertilizer of 5:5:5 (Hyponex, Osaka, Japan) to the irrigation water at a ratio of 1:500.

The experimental system was placed in a climate-controlled growth chamber (KCLP-1500LED-NCS, NK-system, Japan) $151.2 \mathrm{~cm}$ in height, $120 \mathrm{~cm}$ in width, and $80 \mathrm{~cm}$ in length. In the experiment, two environmental conditions were manually controlled at each day. The chamber was illuminated with fluorescent lamps under condition 1 (8:00 am-10:00 pm); and the lamps were turned off under condition 2 (10:00 pm-8:00 am). Air temperature and maximal humidity were set at $30^{\circ} \mathrm{C}$ and $60 \%$ at condition 1 and $22^{\circ} \mathrm{C}$ and $60 \%$ at condition 2 . The microclimate inside the growth chamber was measured using an air temperature-humidity sensor (HMP-155, Vaisala, Vantaa, Helsinki, Finland), a solar radiation sensor (LI-190, Li-Cor, Lincoln, NE, U.S.A.) and a $\mathrm{CO}_{2}$ sensor (GMT-222, Vaisala). The experiment was conducted from September $28^{\text {th }}, 2016$ to January $23^{\text {rd }}, 2017$, which covered the period from crop transplantation to fruit bearing. The mean values of the measured environmental parameters through the experiment are shown in Table 1.

\section{WUE analysis}

Figure 3 shows the framework of WUE analysis. The quantitative growth of the cultivated crop was focused by observing crop growth indices and analyzed the relationship between water use and crop growth. Soil moisture dynamics was observed to confirm that water supplied to the rooting zone was absorbed by the crop. At the end of the experiment, crop yield and total water absorption were used to determine the WUE. Comparison was made with previous highefficiency crop production to assess the WUE in water-saving cultivation.

The soil water retention zone was visually observed by removing a small amount of dry soil from the soil surface to the wetting front. This visual observation was conducted for pot 1 several times during the growing period. Pot 2 served as a static reference for which observation was conducted only once at the end of the experiment. We also observed the growth height and daily supply water volume of both pots for growth analysis. These were non-penetrative observations. When cultivation of pot 1 was ended, we observed the shape and volume of the water retention zone by digging out the water retention zone from the cultivated soil (Li et al., 2018a).

Reference soil moisture was confirmed using the oven dry method by collecting three soil samples at wet, dry, and boundary area. Physiological symptom was also observed to be closely related to water absorption activity. The precision observation of soil moisture dynamics using the soil moisture sensor matrix was developed in our previous paper (Usui et al., 2017; Li et al., 2018a). There are different growth indices to reflect the growth of tomatoes. In the study, parameters were plant height, number of branches, and number of fruits. The corresponding water use during the crop growth was recorded. After the first fruit ripened, water supply was stopped for 5 days to stabilize the water flow in the rooting zone. The soil water retention zone was taken out of the soil for measurement of wet soil volume and root distribution (Li et al., 2018b). The dry biomass of roots and shoots and

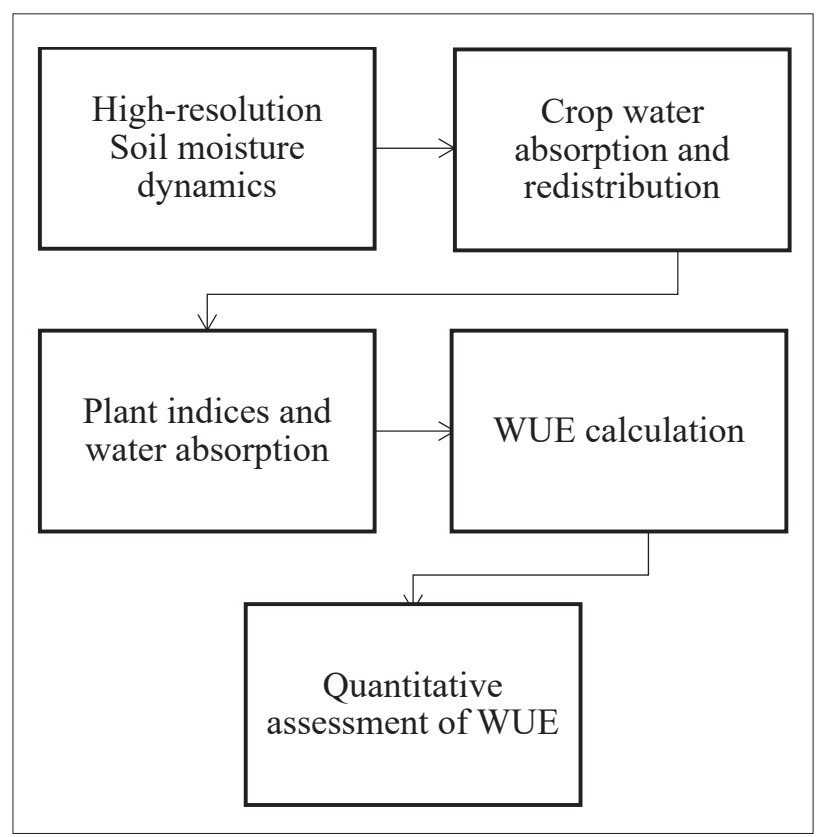

FIGURE 3. Framework of water use efficiency (WUE) analysis in this study. 


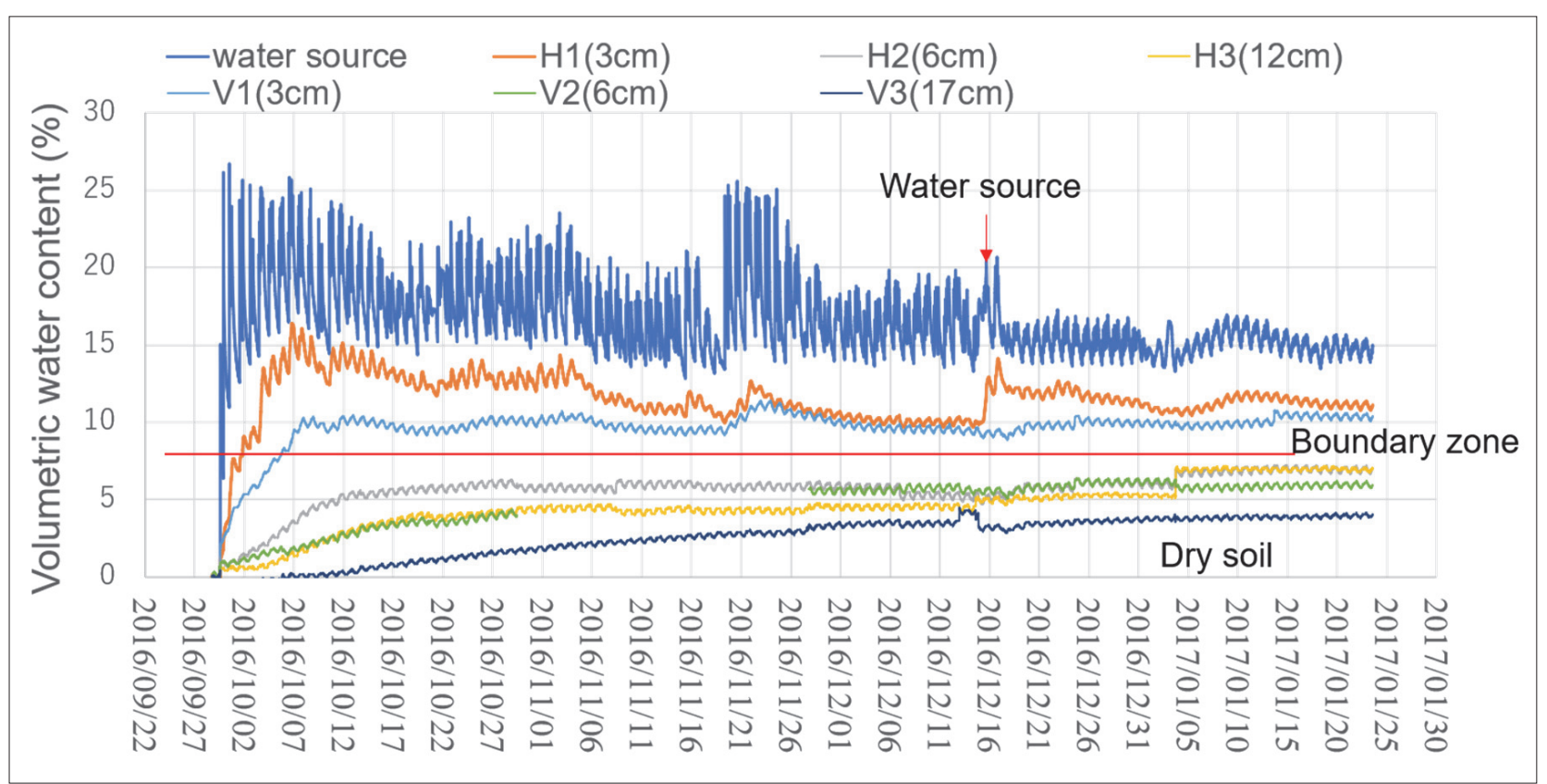

FIGURE 4. Soil moisture dynamics at the positions of water source, distance from the water source horizontally (H1, H2, H3) and vertically (V1, V2, V3) during the experiment.

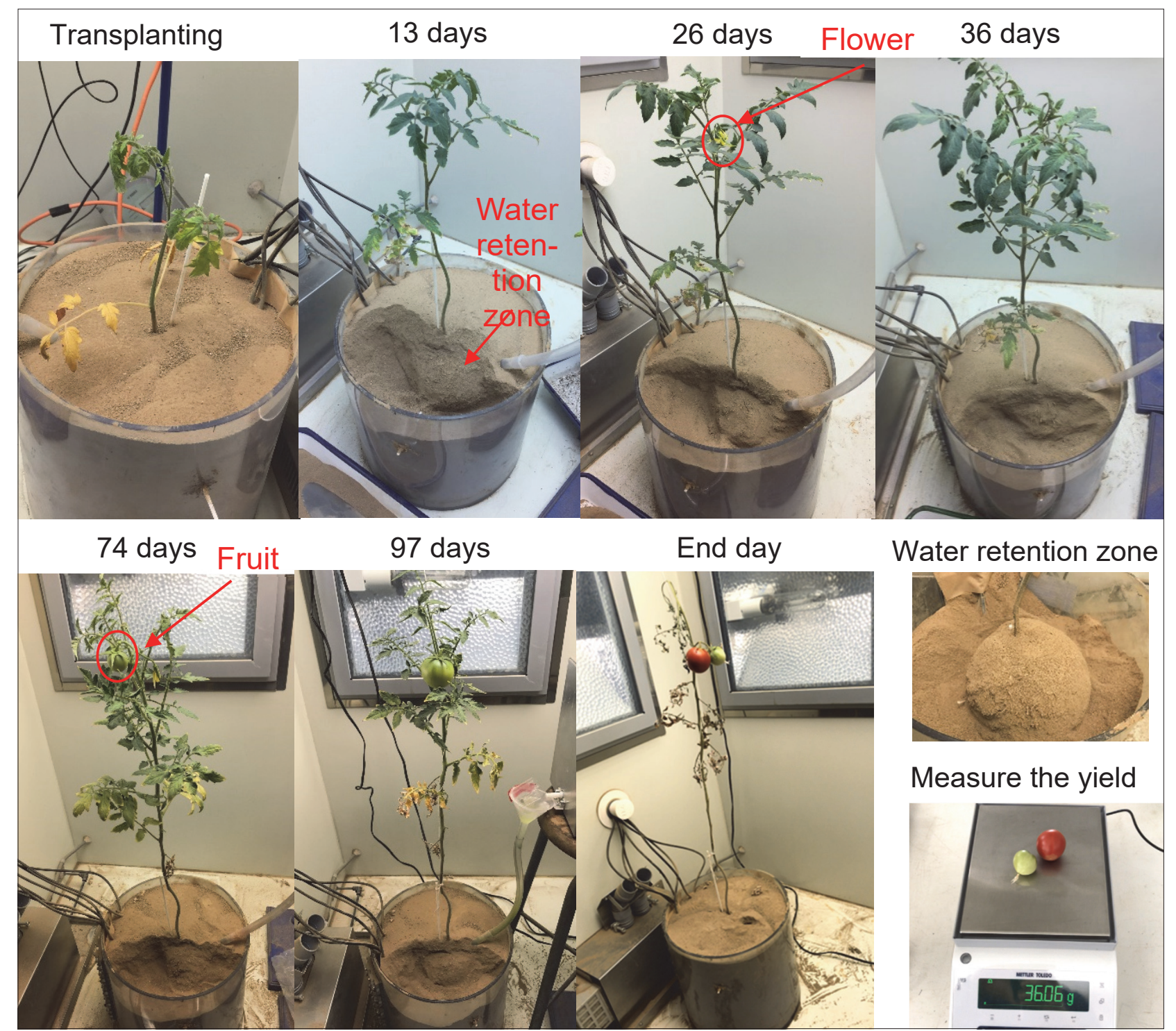

FIGURE 5. Observation of plant growth and water retention during the experiment. 
the fruit weight were measured. Roots were carefully sieved and washed to separate them from the soil and then dried in the oven at $80^{\circ} \mathrm{C}$ for $24 \mathrm{~h}$ to obtain the dry biomass. Wilted branches around the pots were collected for the observation. Because the existence of the water retention zone was visually confirmed during crop growth and evaporation from the soil surface was not observed (Li et al., 2018a), it was assumed that the water supplied to the water retention zone was almost all absorbed by the crop. WUE was calculated using the ratio of fruit weight to crop water absorption. Finally, WUE was compared to previous high-efficiency water-saving data to assess crop physiological characteristics in the watersaving cultivation.

\section{Results}

\section{Soil moisture dynamics in the rooting zone}

The following analysis focused on pot 1 because pot 2 yielded quite similar results. Soil moisture analysis was based on the same method used in previous work (Li et al., 2018a). Soil moisture dynamics throughout the experiment period are shown in Figure 4. The top curve represents soil moisture response at the water source. Each peak represents a single water supply event. Moisture value at this position varied around $15 \%$ to $20 \%$. The curves $\mathrm{H} 1, \mathrm{H} 2$ and $\mathrm{V} 1, \mathrm{~V} 2$, respectively, are soil moisture at positions $3 \mathrm{~cm}, 6 \mathrm{~cm}$ from the water source horizontally (H1, H2) and vertically (V1, V2). These values indicated moisture at the boundary zone between wet and dry soil. The curves $\mathrm{H} 3$ and V3 show measurements of, respectively, dry soil $12 \mathrm{~cm}$ from the water source horizontally and $17 \mathrm{~cm}$ from the water source vertically. These values confirmed that the water supply did not cause excessive water flow into the dry soil. As a result, the moisture distribution was observed in the rooting zone, in $\mathrm{cm}$ order resolution. The soil moisture values were transferred to water potential through a water retention curve of the experiment soil. The $\mathrm{pF}$ value at the water source varied around pF $3.4(15 \%)$ to $\mathrm{pF} 3.0$ (20\%). In this experiment, $\mathrm{pF} 3.4$ was the wilting point and can be treated as a threshold for water supply. The crop recovered from wilting by absorbing water after each water supply event when water potential peaked around pF 3.0. The crop cannot absorb water from the dry soil where the water potential is much lower than the wilting point.

\section{Observation of crop growth and crop water supply}

Water retention was observed across the growth cycle as shown in Figure 5. Water retention was stable in the rooting zone during the crop growth, but symptoms of water stress can be seen such as reduced leaves and branch loss to conserve water and reduce energy load. A flower abortion was also observed during flower setting, which may directly influence crop yield (Khapte et al., 2019).

The relationship between plant height and cumulative water supply for pot 1 is shown in Figure 6. A linear relationship between the plant's height and the cumulative water

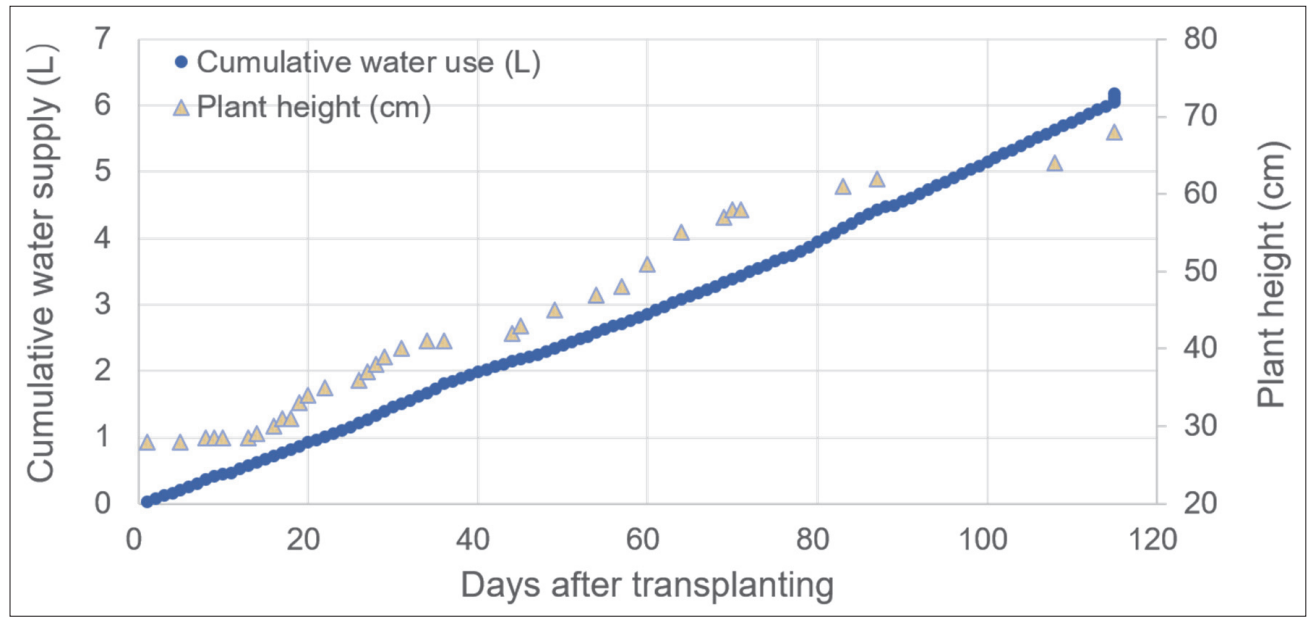

Figure 6. Plant height and cumulative water supply.

TABLE 2. Crop growth indices and cumulative water usage.

\begin{tabular}{lcc}
\hline & Pot 1 & Pot 2 \\
\hline Height at transplantation $(\mathrm{mm})$ & 280 & 200 \\
Height at the end of the experiment $(\mathrm{mm})$ & 680 & 580 \\
Growth rate through the experiment $\left(\mathrm{mm}\right.$ day $\left.^{-1}\right)$ & 5.0 & 4.6 \\
Day of the fruit setting after transplantation & 68 & 70 \\
Growth rate before fruit setting $\left(\mathrm{mm} \mathrm{day}^{-1}\right)$ & 5.5 & 4.8 \\
Growth rate after fruit setting $\left(\mathrm{mm} \mathrm{day}^{-1}\right)$ & 2.1 & 4.3 \\
Cumulative water absorption at the first fruit setting (L) & 3.28 & 4.16 \\
\hline
\end{tabular}

TABLE 3. Crop yield and water use efficiency (WUE).

\begin{tabular}{ccccccc}
\hline & $\begin{array}{c}\text { Dry } \\
\text { biomass }\end{array}$ & $\begin{array}{c}\text { Number of } \\
\text { fruits }\end{array}$ & $\begin{array}{c}\text { Fruit weight } \\
(\mathrm{g})\end{array}$ & $\begin{array}{c}\text { Total water absorption } \\
(\mathrm{L})\end{array}$ & $\begin{array}{c}\text { WUE } \\
(\mathrm{g} \mathrm{L}-1)\end{array}$ & $\begin{array}{c}\text { Liters to produce } 1 \mathrm{~kg} \text { tomato } \\
(\mathrm{L})\end{array}$ \\
\hline Pot 1 & 6.12 & 2 & 36.06 & 5.84 & 6.17 & 162 \\
Pot 2 & 4.71 & 1 & 32.14 & 6.72 & 4.78 & 209 \\
\hline
\end{tabular}


supply can be observed. The plants' height at transplantation were $280 \mathrm{~mm}$ which increased to $680 \mathrm{~mm}$ at the end of the experiment (Table 2). The cumulative water supply during the experiment was $5.84 \mathrm{~L}$ (Table 3 ). The results indicated that the water supplied into the water retention zone was consumed by the crop for transpiration and photosynthesis, and water is a limit factor to the crop growth.

In this study, extended life cycle and reduced yield was observed for the cultivated crops. The growth rate of tomato was $5.0 \mathrm{~mm}$ day $^{-1}$ for pot 1 and $4.6 \mathrm{~mm}$ day $^{-1}$ for pot 2 (Table 2). The first fruit setting was at around 70 days after transplantation. Cumulative water supply at the first fruit setting was $3.28 \mathrm{~L}$ and $4.16 \mathrm{~L}$ for pot 1 and pot 2 , respectively (Table 2).

\section{Crop yield and water use efficiency}

The dry biomass, yield, total water usage, and crop water absorption at the end of the experiment are shown in Table 3. The WUE was calculated using the ratio of fruit weight to crop water absorption. For comparison, the amount of water used to produce $1 \mathrm{~kg}$ of tomatoes was calculated from previous studies (Stanghellini et al., 2003). As shown in Table 3, the total water usage in this study was $5.84 \mathrm{~L}$ and $6.72 \mathrm{~L}$, respectively, for pot 1 and pot 2 , and the corresponding yield was $36.06 \mathrm{~g}$ and $32.14 \mathrm{~g}$.

\section{Discussion}

\section{Relationship between root water uptake and WUE}

In order to study WUE during water supply and crop water absorption, the soil moisture change rate at day 70 was focused (Figure 7). Soil moisture change at the water source varied between 0.28 and $-0.16 \% \mathrm{~min}^{-1}$. Values at other places were between 0.02 to $-0.01 \% \mathrm{~min}^{-1}$. In our system, water flow mainly depended on infiltration from water source and root water uptake. Thus, the positive response of soil moisture change represents infiltration, while the negative response is a sign of root water uptake (Shukri et al., 2013). In this case, infiltration and root water uptake were the most effective on soil moisture at positions close to the water source, which was supposed to be the center of the crop rooting zone (Li et al., 2018b). The moisture at other positions changed very little, which indicated a balanced state of soil moisture at these positions. Therefore, the water supply used in this study ensured a small but adequate amount of available water in the rooting zone for crop growth. As the water supply attempted to meet the minimal level of crop water absorption, a very small amount of water was supplied to the rooting zone to compensate for the water depleted by the root. After the water was taken up by the root, a reduction of soil moisture occurred in the soil surrounding the root. This moisture reduction induced negative pressure in the soil, and water flowed towards this region from nearby soil. This phenomenon can explain the vibration of the moisture change at the water source in Figure 7.

In this study, it can be assumed that the soil moisture dynamics in the rooting zone reflect the characteristics of crop water absorption (Shukri et al., 2013, 2014). After each water supply event, the moisture at the water source peaked with a time constant of about $30 \mathrm{~min}$ and then gradually decreased due to water uptake by roots. Thus, the moisture change rate reflects the crop water absorption rate. Decrease of water absorption rate may indicate that the soil moisture cannot meet the crop's water absorption requirement, and this point should mark the start of water supply.

The moisture bonded in the rooting zone depends not only on infiltration but also water absorption by roots. The spatial and temporal dynamics of the soil moisture in the rooting zone are thus closely related to the biological activity of the crop. A balanced moisture state can be interrupted by accumulated moisture in the soil. So higher WUE in irrigation practice can be achieved when the available water in the rooting zone is improved in response to the root water uptake. The soil moisture dynamics measured in this study indicate that irrigation can be adjusted to respond to crop biological activities and that WUE can be an index to evaluate the effectiveness of irrigation management in response to crop water absorption requirements.

\section{Physiological implications of WUE assessment}

A direct response of a plant to drought is stomatal closure, which may protect the plant from dehydration while simultaneously reducing the $\mathrm{CO}_{2}$ assimilation, resulting in a lower growth rate. On the other hand, severe drought stress may lead to increase of excessive photon energy in chloroplasts and production of reactive oxygen species and caus-

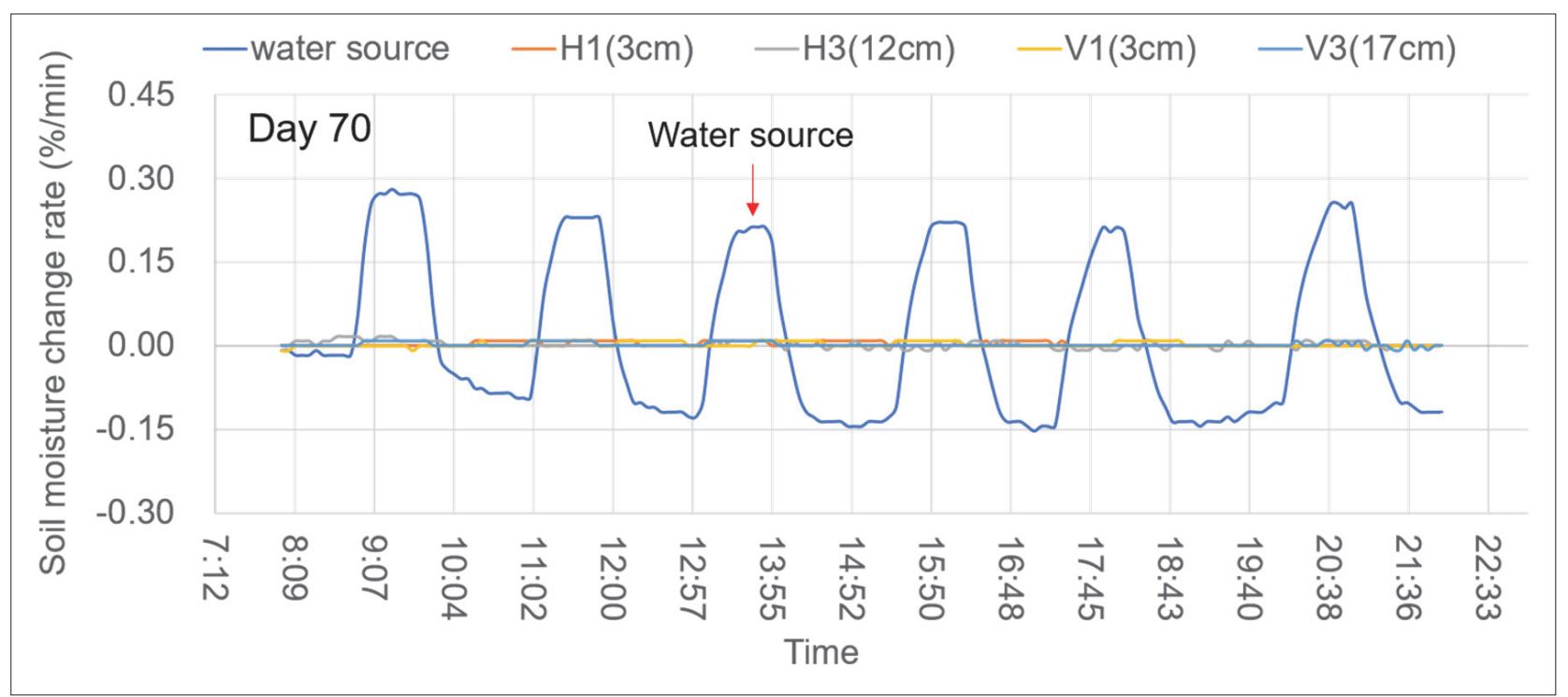

FIGURE 7. Soil moisture change rate at each monitor position at day 70 after transplantation. 
TABLE 4. Liters of water to produce $1 \mathrm{~kg}$ of tomatoes in previous studies (Stanghellini et al., 2003; Shukri, 2014).

\begin{tabular}{lc}
\hline & $\begin{array}{c}\text { Liters to produce } \\
1 \mathrm{~kg} \text { tomato }(\mathrm{L})\end{array}$ \\
\hline Field production (Israel and Almeria) & 60 \\
Plastic house (America,1990) & 40 \\
Glass house (TUAT fibrous system) & 34 \\
Plastic house (Israel) & 30 \\
Improved plastic house (Almeria, 2000) & 27 \\
Glass house (TUAT controlled fibrous system) & 22 \\
\hline
\end{tabular}

ing the peroxidation of membrane lipids, and finally damage photosynthetic apparatus (Elsheery and Cao, 2008). The defense mechanism involves transferring light energy through non-photochemical quenching (NPQ), increasing activities of antioxidant, accumulation of osmolyte compounds and reducing morphological, physiological, biochemical characteristics (Elsheery and Cao, 2008; Bolat et al., 2016). In this study, reduced leaf area was observed which may be caused by the defense mechanism to reduce the energy load under the severe drought stress. As a result, a slow growth rate and extended fruiting period was observed due to the low photosynthesis rate. Fruit setting represents a change in growth stage between nutrient growth and fruit development. The growth rate became slower for the tomato samples at this stage (Table 2), which indicated that the crops needed to allocate biomass to the reproductive organs during fruit development. The results suggest that an improvement of the water supply is a key issue to maintain the growth rate of crop. Taken together, the findings indicate that the watersaving cultivation used in this study could not sustain multi- ple biological processes such as cell enlargement, metabolic processes, and leaf development, which resulted in an extended life cycle, lower number of fruits, and reduced fruit size (Misra et al., 2002; Suresh et al., 2014).

Table 4 shows the amount of water used to produce $1 \mathrm{~kg}$ of tomatoes in this study and previous studies. The previous studies highlighted here were recognized as high-efficiency crop production (Stanghellini et al., 2003; Shukri, 2014). The WUE reported in these studies was an overall ratio of total yield to estimated evapotranspiration or irrigation water usage. As such, it does not reflect crop's physiological characteristics under absolute water-saving conditions or water absorption conditions. By contrast, the WUE reported in this study was the ratio of crop yield to the water used by the crop. Thus, the crop's physiological characteristics can be assessed. Because the amount of water supplied in the rooting zone only led to a very small level of crop growth in this study, its WUE can be considered a new index marking the limit of crop survival.

The volume of water used to produce $1 \mathrm{~kg}$ tomatoes is about 7 times higher than that used in the glass house production with a controlled capillary system developed in our previous program by Tokyo University of Agriculture and Technology (TUAT). The total water usage was about $1 / 20$ of the TUAT result with the yield about 133 times lower and the cultivation period about 1.5 times longer (Shukri, 2014). Given these results, it seems water application is not proportional to the yield. Even though almost all irrigation water was absorbed by the crop, the corresponding yield was not at a level equivalent to previous studies. Several reasons may explain this phenomenon.

First, the calculation of WUE was based on fruit weight when the first fruit matured, and a large portion of the water absorbed by the plant was used for nutrient growth. Due to

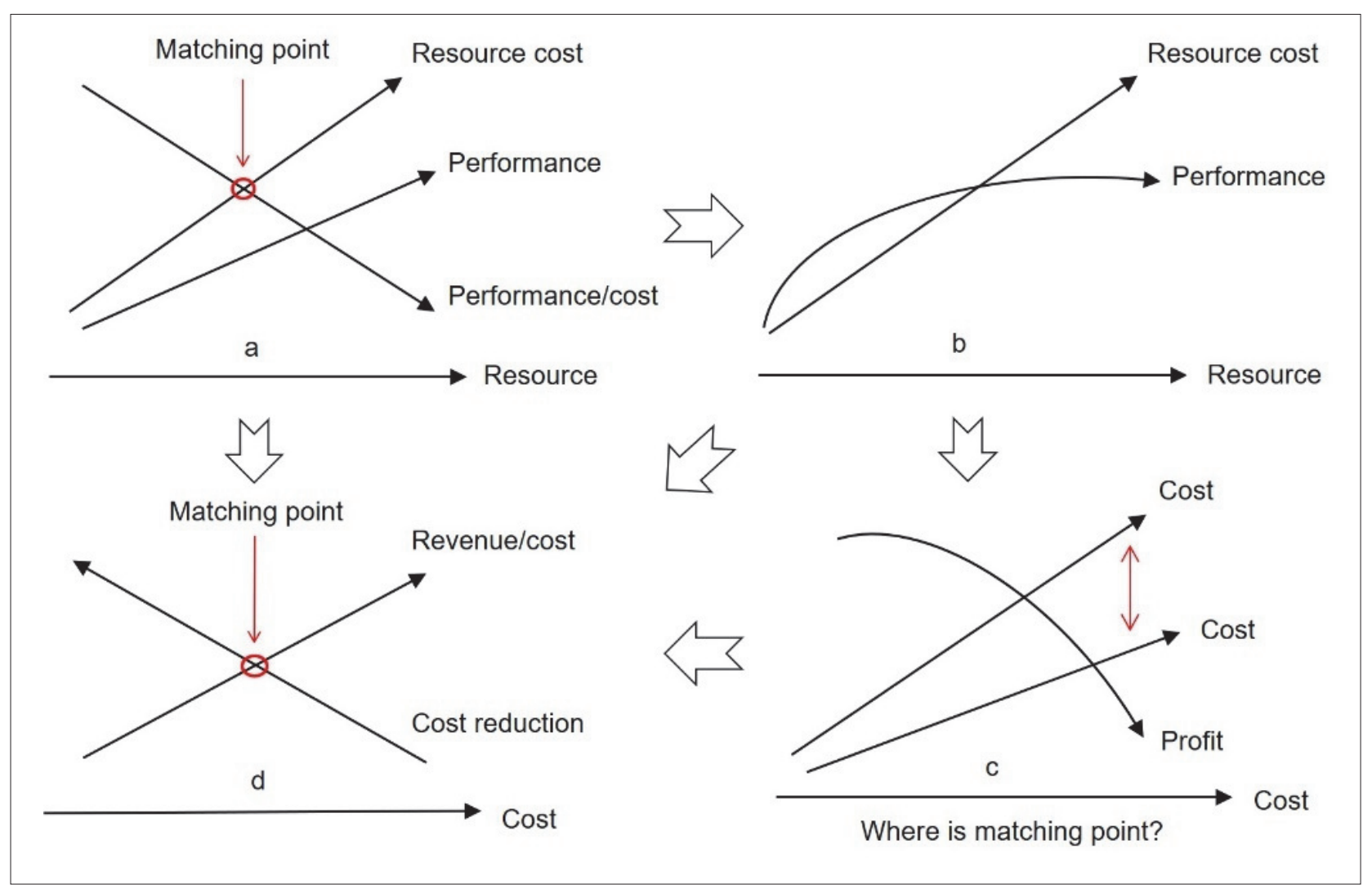

FIGURE 8. Scheme of investigating the matching point of cost and revenue in deficit irrigation. 
the restricted water application in this study, crops experienced water stress, which caused a lower growth rate and eventually reduced yield. The growth retardance observed in this study can also be attributed to the crops' protection mechanism to over-reduce growth in order to survive environmental stress (Maggio et al., 2018). Faced with reduced soil moisture, crops develop strategies to maintain tissue water content, which allows crops to conserve limited water resource to overcome extreme drought, leading to marginal growth.

\section{Economic implications of WUE assessment}

The crop yield response to water use can be described using the crop productivity function. Researches revealed that this function had a logistic characteristic (English et al., 2002; Geerts and Raes, 2009). The maximum WUE appeared to occur at the point before the maximum yield was reached, which indicates that reducing a fraction of irrigation water may improve WUE by improving yield and reducing water loss. A deficit irrigation method depends on proper management of water stress that allows crops to sustain some degree of water deficit with a significant reduction of irrigation water. When water is a scarce resource such as in arid land, increasing water application may not improve the net profit due to the relatively high cost associated with the resource use. And deficit irrigation becomes more profitable than full irrigation because it focuses on maximizing net income by optimizing water use (English et al., 2002).

Figure 8 shows the discussion scheme of complicated factors of revenue and cost under deficit irrigation condition. Major point of our aim is to optimize such complicated factors and investigating the well-matched point of these factors, using the measured WUE value. In Figure 8a, increasing the yield may not increase the net income because the maximum relative yield per unit of water was reached. In this situation the performance/cost ratio of the system decreases with the increase of water application. To optimize water use, a matching point between cost and performance needs to be predicted. Figures $8 \mathrm{~b}$ and $8 \mathrm{c}$ indicate the cost performance when yield reached maximum. In this situation, a matching point may not be reached because the system performance becomes saturate and any increases of water resource may decrease the net profit. According to these thoughts, a cost reduction effort is required when the revenue/cost and cost have a reverse relationship to balance the trade-off between cost and performance. English (1990) and English et al. (2002) illustrated that the optimum water application occurs at the point when marginal cost just equal to the marginal product when water is a limiting factor. Therefore, the matching point of cost reduction and revenue/cost ratio indicates that the WUE of the cultivated crops equals to the cost efficiency of the water resource. And the index of WUE proposed in this study can precisely assess the economic efficiency of individual crop which may contribute to prediction of optimal water application in deficit irrigation.

\section{Conclusions}

This paper proposes a new method to determine WUE: as the ratio of crop yield to total water absorption based on actual water absorption determined from micro soil water dynamics in the crop rooting zone. The WUE obtained from this method forms a new index that reflects crop's physiological characteristics and status under absolute water-saving conditions. A case study was provided to experimentally verify the method under an extreme water-saving condition.
In the case study, the water supply ensured a small level of crop water absorption. The physiological crop response was observed, and comparisons were made to previous precision cultivation studies where WUE was obtained from overall estimations. By comparison, the WUE in our case study was extremely low, and the crops showed symptoms of growth retardation. These results indicate that crops' physiological activity strategically restrained crop growth to ensure survival. The experiment verified the feasibility of studying micro soil water dynamics to analyze crop WUE and using WUE as an index to compare physiological characteristics between individual crops under absolute water-saving conditions. To compare between varieties, studies of more samples are needed to obtain rigorous and stable WUE measurements. The WUE index can be used to evaluate the effectiveness of irrigation management throughout the cultivation process in response to crop water absorption in deficit irrigation. Detailed measurements of crop-water characteristics also contribute to prediction of optimal water application in deficit irrigation.

\section{Acknowledgments}

This study was supported by the Guangxi Science and Technology Major Project (GUIKE AA18118037) and the Key Laboratory Project of CAU (2019TC124).

\section{References}

AQUASTAT (2016). Water withdrawal by sector, around 2010. http:// www.fao.org/nr/water/aquastat/tables/WorldData-Withdrawal_ eng.pdf.

Albasha, R., Mailhol, J., and Cheviron, B. (2015). Compensatory uptake functions in empirical macroscopic root water uptake models - Experimental and numerical analysis. Agr. Water Mgt. 155, 22-39. https://doi.org/10.1016/j.agwat.2015.03.010.

Bacon, A.M. (2004). Water Use Efficiency in Plant Biology, $1^{\text {st }}$ edn. (Oxford, U.K.: Blackwell Publishing).

Baluška, F., Mancuso, S., Volkmann, D., and Barlow, P.W. (2009). The 'root-brain' hypothesis of Charles and Francis Darwin. Plant Signal. Behav. 12,1121-1127. https://doi.org/10.4161/psb.4.12.10574.

Bolat, I., Dikilitas, M., Ikinci, A., Ercisli, S., and Tonkaz, T. (2016). Morphological, physiological, biochemical characteristics and bud success responses of myrobolan 29c plum rootstock subjected to water stress. Can. J. Plant. Sci. 96, 485-493.

Brunel, J., Walker, G.R., and Kennett-Smith, A.K. (1995). Field validation of isotopic procedures for determining sources of water used by plants in a semi-arid environment. J. Hydrol. 167, 351-368. https://doi.org/10.1139/cjps-2015-0260.

Burke, S., Mulligan, M., and Thornes, J.B. (1999). Optimal irrigation efficiency for maximum plant productivity and minimum water loss. Agr. Water Mgt. 40, 377-391. https://doi.org/10.1016/S03783774(99)00011-6.

Cai, G., Vanderborght, J., Couvreur, V., Mboh, C.M., and Vereecken, H. (2018). Parameterization of root water uptake models considering dynamic root distributions and water uptake compensation. Vadose Zone J. 17, 160125. https://doi.org/10.2136/vzj2017.11.0201.

Cassiani, G., Boaga, J., Rossi, M., Putti, M., Fadda, G., Majone, B., and Bellin, A. (2016). Soil-plant interaction monitoring: Small scale example of an apple orchard in Trentino, North-Eastern Italy. Sci. Total Environm. 543, 851-861. https://doi.org/10.1016/j. scitotenv.2015.03.113.

Consoli, S., Stagno, F., Vanella, D., Boaga, J., Cassiani, G., and Roccuzzo, G. (2017). Partial root-zone drying irrigation in orange orchards: Effects on water use and crop production characteristics. Eur. J. 
Agron. 82, 190-202. https://doi.org/10.1016/j.eja.2016.11.001.

Costa, J.M., Ortuño, M.F., and Chaves, M.M. (2007). Deficit irrigation as a strategy to save water: Physiology and potential application to horticulture. J. Integr. Plant. Biol. 49, 1421-1434. https://doi. org/10.1111/j.1672-9072.2007.00556.x

Coyago-Cruz, E., Meléndez-Martínez, A.J., Moriana, A., Girón, I.F., Martín-Palomo, M.J., Galindo, A., Pérez-López, D., Torrecillas, A. Beltrán-Sinchiguano, E., and Corell, M. (2019). Yield response to regulated deficit irrigation of greenhouse cherry tomatoes. Agr. Water Mgt. 213, 212-221. https://doi.org/10.1016/j.agwat.2018.10.020.

Elsheery, N.I., and Cao, K. (2008). Gas exchange, chlorophyll fluorescence, and osmotic adjustment in two mango cultivars under drought stress. Acta Physiol. Plant. 30, 769-777. https://doi. org/10.1007/s11738-008-0179-x.

Elsheery, N.I., Sunoj, V.S.J., Wen, Y., Zhu, J.J., Muralidharan, G., and Cao, K.F. (2020a). Foliar application of nanoparticles mitigates the chilling effect on photosynthesis and photoprotection in sugarcane. Plant Physiol. Biochem. 149, 50-60. https://doi.org/10.1016/j. plaphy.2020.01.035.

Elsheery, N.I., Helaly, M.N., El-Hoseiny, H.M., and Alam-Eldein, S.M. (2020b). Zinc oxide and silicone nanoparticles to improve the resistance mechanism and annual productivity of salt-stressed Mango trees. Agronomy 10, 558. https://doi.org/10.3390/ agronomy10040558.

English, M.J. (1990). Deficit irrigation: I. Analytical Framework. J. Irrig. Drain Engin. 116, 399-412. https://doi.org/10.1061/ (ASCE)0733-9437(1990)116:3(399).

English, M.J., Solomon, K.H., and Hoffman, G.J. (2002). A paradigm shift in irrigation management. J. Irrig. Drain Engin. 128, 267-277. https://doi.org/10.1061/(ASCE)0733-9437(2002)128:5(267).

Frenken, K., and Gillet, V. (2012). Irrigation water requirement and water withdrawal by country (FAO Aquastat Reports).

Geerts, S., and Raes, D. (2009). Deficit irrigation as an on-farm strategy to maximize crop water productivity in dry areas. Agr. Water Mgt. 96, 1275-1284. https://doi.org/10.1016/j.agwat.2009.04.009.

Greve, A.K., Acworth, R.I., and Kelly, B.F.J. (2011). 3D Crosshole resistivity tomography to monitor water percolation during irrigation on cracking soil. Soil Res. 49, 661. https://doi. org/10.1071/SR11270.

Helaly, M.N., El-Hoseiny, H., El-Sheery, N.I., Rastogi, A., and Kalaji, H.M. (2017). Regulation and physiological role of silicon in alleviating drought stress of mango. Plant Physiol. Biochem. 118, 31-44. https://doi.org/10.1016/j.plaphy.2017.05.021.

Hirose, T., Hoshi, S., Miyake, H., and Totsuka, T. (1991). Cyclic changes in the photosynthetic rate and the transpiration rate of peanut leaves. Japan. J. Crop Sci. 60, 504-509. https://doi.org/10.1626/jcs.60.504.

Howell, T.A. (2001). Enhancing water use efficiency in irrigated agriculture. Agron. J. 93, 281-289. https://doi.org/10.2134/ agronj2001.932281x.

Jensen, C.R., Battilani, A., Plauborg, F., Psarras, G., Chartzoulakis, K., Janowiak, F., Stikic, R., Jovanovic, Z., Li, G., Qi, X., et al. (2010). Deficit irrigation based on drought tolerance and root signalling in potatoes and tomatoes. Agr. Water Mgt. 98, 403-413. https://doi. org/10.1016/j.agwat.2010.10.018.

Jones, H.G. (2004). Irrigation scheduling: Advantages and pitfalls of plant-based methods. J. Exp. Bot. 55, 2427-2436. https://doi. org/10.1093/jxb/erh213.

Khapte, P.S., Kumar, P., Burman, U., and Kumar, P. (2019). Deficit irrigation in tomato: Agronomical and physio-biochemical implications. Sci. Hortic. (Amsterdam) 248, 256-264. https://doi.

\section{org/10.1016/j.scienta.2019.01.006.}

Kukal, M.S., and Irmak, S. (2020). Evidence of arithmetical uncertainty in estimation of light and water use efficiency. Sustainability (Basel) 12, 2271. https://doi.org/10.3390/su12062271.

Lenka, N.K., Lenka, S., Thakur, J.K., Yashona, D.S., Shukla, A.K., Elanchezhian, R., Singh, K.K., Biswas, A.K., and Patra, A.K. (2020). Carbon dioxide and temperature elevation effects on crop evapotranspiration and water use efficiency in soybean as affected by different nitrogen levels. Agr. Water Mgt. 230, 105936. https:// doi.org/10.1016/j.agwat.2019.105936.

Li, Q., Sugihara, T., Kodaira, M., and Shibusawa, S. (2018a). Observation and analysis of moisture distribution in rooting zonepractical assessment of precision irrigation method focus on controlled water-retention-zone. Transactions of SICE 54, 91-98. https://doi.org/10.9746/sicetr.54.91.

Li, Q., Sugihara, T., Kodaira, M., and Shibusawa, S. (2018b). Observation of root behavior in a controlled soil water retention zone. Acta Hortic. 1227, 457-462. https://doi.org/10.17660/ ActaHortic.2018.1227.57.

Liu, L., Yang, X., Zhou, H., Liu, S., Zhou, L., Li, X., Yang, J., and Wu, J. (2018). Relationship of root zone soil moisture with solar-induced chlorophyll fluorescence and vegetation indices in winter wheat: A comparative study based on continuous ground-measurements. Ecol. Indic. 90,9-17.https://doi.org/10.1016/j.ecolind.2018.02.048.

Maggio, A., Bressan, R., Zhao, Y., Park, J., and Yun, D. (2018). It's hard to avoid avoidance: Uncoupling the evolutionary connection between plant growth, productivity and stress "tolerance". Int. J. Mol. Sci. 19, 3671. https://doi.org/10.3390/ijms19113671.

Misra, A.N., Biswal, A.K., and Misra, M. (2002). Physiological, biochemical and molecular aspects of water stress responses in plants and the biotechnological applications. Proc. Nat. Acad. Sci. (India).

Morison, J.I.L., Baker, N.R., Mullineaux, P.M., and Davies, W.J. (2007). Improving water use in crop production. Philosophical Transactions of the Royal Society B: Biol. Sci. 363, 639-658. https://doi. org/10.1098/rstb.2007.2175.

Naser, H.M., Hanan, E., Elsheery, N.I., and Kalaji, H.M. (2016). Effect of biofertilizers and putrescine amine on the physiological features and productivity of date palm (Phoenix dactylifera L.) grown on reclaimed-salinized soil. Trees 30, 1149-1161. https://doi. org/10.1007/s00468-016-1353-1.

O'Shaughnessy, S.A., Evett, S.R., and Colaizzi, P.D. (2015). Dynamic prescription maps for site-specific variable rate irrigation of cotton. Agr. Water Mgt. 159, 123-138. https://doi.org/10.1016/j. agwat.2015.06.001.

Omar, S.A., Fu, Q., Chen, M., Wang, G., Song, S., Elsheery, N.I., and $\mathrm{Xu}$, Z.F. (2011). Identification and expression analysis of two small heat shock protein cDNAs from developing seeds of biodiesel feedstock plant Jatropha curcas. Plant Sci. 181, 632-637. https://doi. org/10.1016/j.plantsci.2011.03.004.

Omar, S.A., Elsheery, N.I., Kalaji, H.M., Ebrahim, M.K., Pietkiewicz, S., Lee, C.H., Allakhverdiev, S.I., and Xu, Z.F. (2013). Identification and differential expression of two dehydrin cDNAs during maturation of Jatropha curcas seeds. Biochemistry (Moscow) 78, 485-495. https:// doi.org/10.1134/S0006297913050076.

Raine, S.R., Meyer, W.S., Rassam, D.W., Hutson, J.L., and Cook, F.J. (2007). Soil-water and solute movement under precision irrigation: Knowledge gaps for managing sustainable root zones. Irrig. Sci. 26, 91-100. https://doi.org/10.1007/s00271-007-0075-y.

Rothfuss, Y., and Javaux, M. (2016). Isotopic approaches to quantifying root water uptake and redistribution: A review and 
comparison of methods. Biogeosci. Disc. 14, 2199-2224. https://doi. org/10.5194/bg-2016-410.

Shukri, B.Z.A.M. (2014). Capillary-based Subsurface Irrigation System for Water-saving Agriculture (Tokyo University of Agriculture and Technology).

Shukri. B.Z.A.M., Shibusawa, S., Ohaba, M., Li, Q., and Marzuki, B.K. (2013). Water uptake response of plant in subsurface precision irrigation system. Engin. Agric. Environm. Food 6, 128-134. https:// doi.org/10.1016/S1881-8366(13)80022-5.

Shukri. B.Z.A.M., Shibusawa, S., Ohaba, M., Li, Q., and Bin Khalid, M. (2014). Capillary flow responses in a soil-plant system for modified subsurface precision irrigation. Precis. Agric. 15, 17-30. https://doi org/10.1007/s11119-013-9309-6.

Sinclair, T.R. (2018). Effective water use required for improving crop growth rather than transpiration efficiency. Front. Plant Sci. 9. https://doi.org/10.3389/fpls.2018.01442.

Singh, R.K., Deshmukh, R., Muthamilarasan, M., Rani, R., and Prasad, M. (2020). Versatile roles of aquaporin in physiological processes and stress tolerance in plants. Plant Physiol. Biochem. 149, 178-189. https://doi.org/10.1016/j.plaphy.2020.02.009.

Sonkar, I., Kotnoor, H.P., and Sen, S. (2019). Estimation of root water uptake and soil hydraulic parameters from root zone soil moisture and deep percolation. Agr. Water Mgt. 222, 38-47. https://doi. org/10.1016/j.agwat.2019.05.037.

Stanhill, G. (1986). Water use efficiency. Adv. Agron. 39, 53-85. https://doi.org/10.1016/S0065-2113(08)60465-4.

Suresh, P.K., Minhas, P.S., Govindasamy, V., and Choudhary, R.L. (2014). Influence of moisture stress on growth, development, physiological process and quality of fruits and vegetables and its management strategies. In Approaches to Plant Stress and their Management, R.K. Gaur, and P. Sharma, eds. (Springer), p. 124-148.

Takahashi, F., Suzuki, T., Osakabe, Y., Betsuyaku, S., Kondo, Y., Dohmae, N., Fukuda, H., Yamaguchi-Shinozaki, K., and Shinozaki, K. (2018). A small peptide modulates stomatal control via abscisic acid in longdistance signalling. Nature 556, 235-238. https://doi.org/10.1038/ s41586-018-0009-2.

Usui, K., Ban, T., Shibusawa, S., and Sugihara, T. (2017). Highresolution observation of soil water dynamics in the rooting zone: A case study for blueberry plants (IEEE). https://doi.org/10.1109/ SII.2017.8279208.

Vrugt, J.A., Van Wijk, M.T., Hopmans, J.T., and Simunek, J. (2001). One, two, and three-dimensional root water uptake functions for transient modeling. Water Resour. Res. 37, 2457-2470. https://doi. org/10.1029/2000WR000027.

Werban, U., Attia Al Hagrey, S., and Rabbel, W. (2008). Monitoring of root-zone water content in the laboratory by 2D geoelectrical tomography. J. Plant Nutr. Soil Sci. 171, 927-935. https://doi. org/10.1002/jpln.200700145.

Zhao, P., Wang, Y., Yan, S., Fan, L., Wang, Z., Zhou, Q., Yao, J., Cheng, Q., Wang, Z., and Huang, L. (2019). Electrical imaging of plant root zone: A review. Comput. Electron. Agr. 167, 105058. https://doi. org/10.1016/j.compag.2019.105058.
Received: Jun. 4, 2020

Accepted: Nov. 10, 2020

Addresses of authors:

Qichen $\mathrm{Li}^{1}{ }^{1, *}$, T. Sugihara ${ }^{2}$, S. Shibusawa ${ }^{2}$ and Minzan $\mathrm{Li}^{1}$

${ }^{1}$ Key Laboratory of Modern Precision Agriculture System Integration Research of Ministry of Education, China Agricultural University, Beijing 10083, PR China

${ }^{2}$ Institute of Agriculture, Tokyo University of Agriculture and Technology, 3-8-5 Saiwai-Cho, Fuchu, Tokyo 183-8509, Japan

* Corresponding author; E-mail: liqichen9@hotmail.com 